\title{
Crop-raiding macaques: predictions, patterns and perceptions from Langtang National Park, Nepal
}

\author{
Ganga Ram Regmi ${ }^{1,2}$, K. Anne-Isola Nekaris ${ }^{1}$, Kamal Kandel ${ }^{2}$, Vincent Nijman ${ }^{1, *}$ \\ ${ }^{1}$ Department of Anthropology and Geography, Oxford Brookes University, Oxford OX3 0BP, UK \\ ${ }^{2}$ Global Primate Network-Nepal, GPO Box 26288, Kathmandu, Nepal
}

\begin{abstract}
Crop-raiding by wild animals is increasingly known to cause conflict between these animals and humans; subsequent losses incurred by farmers may make communities antagonistic and intolerant towards wildlife protection. There is an increasing need to understand interspecific and geographic differences in patterns of crop-raiding. Here, focussing on macaques, a group of primates that feature high on the list of crop-raiders throughout Asia, we calculate incidence rates (IRs; the proportion of farms where a particular crop is raided by macaques in relation to the total number of farms where this crop is grown and available to macaques) for different crops and relate this to physical and temporal features. Based on interview data from 120 farmers in 3 Village Development Committees in Lantang National Park in Nepal, IRs were highest for potato (0.783) and maize (0.697) and lower for cereals (0.353 and 0.357 for buckwheat and millet, respectively), and IRs of 4 crops were negatively related to the distance to the forest edge. IRs for potato and maize were close to 1 near the forest edge but dropped significantly when the distance between the forest edge and fields exceeded 150 and $400 \mathrm{~m}$, respectively. Farmers mostly employed benign crop-deterrent tactics, but macaques disproportionally raided farms in the early hours of the day, presumably to avoid conflict with farmers. Comparisons with IRs from other macaque species from Sri Lanka and Indonesia show that IRs are not related to caloric or nutritional content of crops or to the quantities in which crops are grown. With respect to the management of macaques and mitigating conflict due to crop-raiding, we advocate an integrative approach taking into account both the IRs and the interactions among macaques, crops and farmers but also the relations among the farmers themselves and the local authorities.
\end{abstract}

KEY WORDS: Cercopithecidae $\cdot$ Conservation attitudes $\cdot$ Crop-raiding risk $\cdot$ Human-wildlife conflict · Management

Resale or republication not permitted without written consent of the publisher

\section{INTRODUCTION}

Crop-raiding by wild animals is increasingly known to be a source of conflict between the animals and humans, perhaps especially so along the boundaries of protected areas (Strum 1994, NaughtonTreves 1998, Sekhar 1998, Gillingham \& Lee 2003, Linkie et al. 2007, Riley 2007). The losses incurred by farmers may make communities living close to protected areas antagonistic and intolerant towards wildlife, which can undermine and impede conservation strategies (Nyhus et al. 2000). Because farmers in developing countries often have limited access to cash and are rarely compensated for their losses, the individual economic losses suffered from crop-raiding can be relatively high (Nyhus et al. 2005, Linkie et al. 2007, Warren et al. 2007). Furthermore, farmers' inability to mitigate crop-raiding adequately and the absence of compensation schemes may lead to retaliatory killing of problem species (Jackson \& Wangchuk 2001, Nyhus et al. 2005). Several studies have found that proximity of a farm to the forest edge and the presence or absence of neighbouring farms best explains the likelihood of any farm sustaining 
crop damage (Hill 2002, Priston 2005, Warren et al. 2007, Nijman \& Nekaris 2010a,b, Wallace 2010). Hence, it seems that farmers that reside close to the border of protected forest reserves or that cultivate crops within the park boundaries are especially vulnerable to crop-raiding.

While many species raid cultivated crops (e.g. insects, rodents, birds and livestock), primates in particular can be significant pests because of their opportunism, adaptability, intelligence and manipulative abilities (Naughton-Treves 1998, Sillero-Zubiri \& Switzer 2001, Warren et al. 2007). Farmers' perceptions of the most notorious crop pests are often influenced by factors other than crop damage (NaughtonTreves et al. 1998, Hill 2004, Naughton-Treves \& Treves 2005). The generally high visibility of, and crop-raiding strategies employed by, primates compared to other crop-raiders may lead farmers to perceive primates to be even more important cropraiders than they already are; this has important management implications.

In Africa, baboons Papio spp. and vervets Chlorocebus spp. top the list of crop-raiding primates (King \& Lee 1987, Saj et al. 2001, Sillero-Zubiri \& Switzer 2001, Warren et al. 2007, Wallace 2010). Throughout most of Asia, the macaques Macaca spp. are perceived as the most important culprits (Pirta et al. 1997, Knight 1999, Marchal 2005, Linkie et al. 2007). Crop-raiding by Japanese macaques M. fuscata has been studied since the 1960s (e.g. Sprague \& Iwasak 2006, Agetsuma 2007, Yamagiwa 2008, Nakagawa et al. 2010, Yamada \& Muroyama 2010). While the number of detailed studies of crop-raiding macaques in other parts of Asia is on the increase (e.g. Priston 2005, Linkie et al. 2007, Riley 2007, Nijman \& Nekaris 2010b, Nekaris et al. 2013), there is still an increasing need for a proper understanding of cropraiding, including interspecific and geographic differences in crop-raiding patterns (cf. Sillero-Zubiri \& Switzer 2001, Gumert et al. 2011). Information on crop-raiding in the only species of non-Asian macaque, M. sylvanus from North Africa, is sparse but conflicts with local people have been reported as a result of crop-raiding (Deag 1977, Butynski et al. 2008).

Here, we report on patterns and perception of crop-raiding by macaques in a farming community located inside the boundaries of an established national park. We also present data on crop-raiding by 3 other macaque species from 3 other regions all collected and analysed in a comparable manner, to provide insights into the perceptions of crop-raiding by macaques in general.
We test the null hypotheses that a crop's incidence rate (IR, the risk of a crop being raided; see 'Materials and methods: Analysis') does not differ among crops and that macaques raid crops irrespective of the location of the fields on which the crops are grown. Cropraiding furthermore has no relation to the nutritional content of crops or the number of farms on which the crops are grown. We assume that farmers protect all crops equally, and thus, we do not expect any temporal differences in raiding events. These predictions should hold for various species of macaques in various regions.

\section{MATERIALS AND METHODS}

\section{Study area}

The government of Nepal established Langtang National Park $\left(85^{\circ} 33^{\prime} \mathrm{E}, 28^{\circ} 12^{\prime} \mathrm{N}\right)$ in 1976 ; it is located in north-central Nepal on the China-Tibet border. Covering an altitudinal range from 800 to $>7200 \mathrm{~m}$ a.s.l., habitats within the park range from subtropical forest to perpetual snow (Sayers \& Norconk 2008). In 1998, the authorities designated $420 \mathrm{~km}^{2}$ in and around the park as a buffer zone. It now encompasses $2130 \mathrm{~km}^{2}$ in 3 districts, viz. Rasuwa, Nuwakot and Sindhupalchowk. Some 45 villages in 26 Village Development Committees are within the park boundaries (Bhuju et al. 2007). From the time of gazettment, the villages have been permitted to farm in the park and are not under the park jurisdiction.

We worked in and with 3 Village Development Committees, Ramche, Syafru and Timure (Rasuwa District), situated within the boundaries of the national park. The villages are relatively compact, and during the last census of 2001, Ramche and Syafru were of a similar size (397 houses and 2153 people in Rachme and 484 houses and 2141 people in Syafru), and Timure was decisively smaller (102 houses and 517 people).

While some villagers gain an income from sporadic village or home-stay tourism, agriculture provides the main livelihood. Maize Zea mays and potatoes Solanum tuberosum are the chief staple crops, with smaller areas dedicated to growing finger millet Eleusine coracana, buckwheat Fagopyrum tataricum and barley Hordeum vulgare. Around their houses, villagers grow additional crops, such as banana Musa spp., for subsistence.

Although the majority of people living in Langtang National Park consider themselves Buddhist or 
Hindu, with associated respect for primates, high incidences of crop-raiding have led to the occasional retaliatory killing of macaques (Chalise \& Johnson 2005, Regmi \& Kandel 2008, Chalise 2010).

\section{Interviews}

We used semi-structured interviews to investigate the farmers' perceptions of crop-raiding by primates. We held interviews in May to July 2007 with 120 household owners ( $\mathrm{n}=40$ in each Village Development Committee, spending $\sim 3$ wk per village) whose farms were situated relatively close to nearby forest areas or vegetated rocky outcrops (median distance $\sim 100 \mathrm{~m}$ for all 3 villages, range 15 to $900 \mathrm{~m}$; measured with a handheld GPS). We sampled an equal number of households per Village Development Committee, representing 8 to $10 \%$ (Ramche and Syafru) and 39\% (Timure) of the village households, to avoid over-representation of the larger villages in our sample. We conducted the interviews in the Nepali language, and the interviews typically lasted between 20 and $30 \mathrm{~min}$. We interviewed farmers one by one to assure independence of the data (cf. Lammertink et al. 2003).

We collected data based on the following topics: the main crops grown; the presence or lack of macaques in the vicinity of the farm; whether or not crop-raiding by macaques occurred; if so, at what time of day this happened most frequently, and which part of the crops were damaged or eaten by the animals. In addition, from those farmers that reported crop-raiding, we obtained data on how they tried to reduce crop-raiding by macaques and what solutions they saw available for reducing conflict with macaques.

\section{Primate surveys}

During the interview period, i.e. May to July 2007, and in October 2007, we surveyed the study area for the presence of macaques. The terrain is steep and hazardous, and by default, our surveys were done on accessible trails only. Here, we walked slowly $\left(\sim 0.5 \mathrm{~km} \mathrm{~h}^{-1}\right)$ and stopped regularly to scan the terrain with binoculars and listen for macaques. In total, an area of $\sim 113 \mathrm{~km}^{2}$ was surveyed. When a group was observed, we counted all individuals (repeated 3 times to increase accuracy), and with the aid of a spotting telescope, we established sex and age composition. The groups' locations upon first sighting were geo-referenced with a hand-held GPS. We made several attempts to follow groups, but given the terrain and the fact that the macaques were not habituated to humans, this proved to be impossible.

We encountered 2 of the 3 primate species present in the park, Assamese macaques Macaca assamensis and Nepal grey langurs Semnopithecus schistaceus, with the former being ubiquitous between elevations of 1300 to $2400 \mathrm{~m}$ a.s.l. and the latter occurring more sparsely above $2000 \mathrm{~m}$ a.s.l. away from the villages. The farmers were able to distinguish between the Assamese macaques and the Nepal grey langurs and to confirm the absence of rhesus macaques $M$. mulatta in their area. With reference to crop-raiding, the Assamese macaque was the most prominent primate species, and our interviews therefore focussed mostly on this species.

The feeding habits of Assamese macaques show great flexibility and differ considerably among regions, with a mainly folivorous diet in southern China (leaves $74 \%$ [primarily bamboo] and fruit $17 \%$ ) and north-eastern India (leaves 52\%, flowers and flower buds $37 \%$ and fruit $11 \%$ ) but a more frugivorous diet in central Thailand (fruit $42 \%$, animal matter 22\% and leaves 21\%) (Srivastava 1999, Schülke et al. 2011, Zhou et al. 2011). Researchers have not studied the diet of Assamese macaques in Langtang National Park in detail, but initial observations suggest that they consume a mixture of leaves (including bamboo shoots) and fruits (G. R. Regmi \& K. Kandel unpubl. data).

\section{Analysis}

The IR is the frequency of new occurrences of a given event, in this case crop-raiding of a particular crop, within a study population within a specified period of time. We calculated IRs for the 4 major crops grown in the study area following the methodology described by Nijman \& Nekaris (2010b). The data needed to calculate the IRs are the availability of a particular crop to the macaques, which is taken here as any crops present at a farm, with the farmer indicating presence of macaques on the fields, and whether or not crop-raiding takes place. Pooling these data across farms provides (1) the total number of farms on which the crop is damaged and (2) the total number of farms where the crop was present and available to crop-raiding macaques. The risk of a crop being raided, the IR, is calculated by dividing factor (1) by factor (2). The higher-risk crops will have an IR closer to 1 . IRs for crop-raiding differ con- 
siderably over time depending on the phenology of the crop (e.g. presence of young growth, ripe fruits, seeds, etc.) and the availability of wild food sources (often with lower levels of crop-raiding when wild food is plentiful). Given that our study period was short relative to the phenological changes in the crops we studied (for instance, in our study area, it takes $\sim 8$ to 9 mo for the maize to ripen completely), we calculated 1 single IR for each of 4 crops. In effect, the IR thus calculated equates to the risk of raiding during this period. Note that IR as defined above is not the same as the proportion of farmers who state that Species $x$ raids Crop $y$ because it crucially refers only to those farms where the crop-raiding species is indeed present at the time the crop is available, and by definition, it is limited to a restricted time period.

We compare our data with other datasets on cropraiding macaques provided that these reported IRs for individual crops or contained enough information for us to calculate them; crucially, information had to be present on the presence of macaques at the time that any particular crop was available. We excluded studies that report on crop-raiding in monocultures; in all studies, farmers cultivated a combination of tubers, cereals and tree crops.

As little is known about the nature of the (statistical) populations from which the samples are drawn, and to increase the generality of the conclusions, non-parametric statistical tests were used (Siegel 1956). Yates' correction for continuity was applied in the chisquared test applications when appropriate. Significance was accepted when $p<0.05$ in a 2-tailed test.

\section{RESULTS}

\section{Nature of crop-raiding}

We observed 9 groups of Assamese macaques in the study area, totalling 213 individuals, with the majority on or near the fields. In addition, we twice observed a single adult male. We saw no Nepal grey langurs near the fields. The median altitude at which we first observed the macaque groups was $1690 \mathrm{~m}$ a.s.l. (interquartile range 1480 to $1800 \mathrm{~m}$ a.s.l.). The macaque groups were widely and thinly spread, with a median nearest distance between groups of $3.10 \mathrm{~km}$ (interquartile range 1.83 to $4.67 \mathrm{~km}$ ). Median group size was 23 ind. (interquartile range 18 to 29 ind.), with $31 \%$ adult females, $16 \%$ adult males, $18 \%$ subadults, $16 \%$ juveniles and $19 \%$ infants.

We observed raiding on crops as described by the farmers (see 'IRs and farm location' and 'Temporal variation in crop-raiding and mitigating damage caused'). Mostly the group as a whole entered the field and raided crops quickly. The longest any group remained in the field was just under $10 \mathrm{~min}$. Macaques stuffed maize or cereal in cheek pouches and carried it off to the nearest forest or rocky outcrop. Once, we observed a single adult male raiding maize in Timure, but farmers in all 3 villages informed us that single adult males frequently raided crops.

Observation of crop-raiding groups revealed that they damaged more than just the crops they actually ate; juveniles and infants in particular caused damage during play on the ground. With respect to the parts damaged (eaten or otherwise), of the farmers who experienced macaques raiding maize, $17 \%$ reported that macaques mainly ate unripe maize cobs, $32 \%$ reported that they mainly ate just-ripe maize cobs, and $51 \%$ reported that they ate ripe and unripe cobs. About half the farmers $(53 \%)$ indicated that macaques ate or damaged all parts of the potato plant, and about $25 \%$ of farmers each indicated that the macaques ate mainly flowers and/or stems or just tubers. Almost all farmers (92\%) of those who reported macaques raiding cereals only experienced raiding of cereals (buckwheat and millet) when the crop was ripe.

\section{IRs and farm location}

In each of the 3 communities, between ca. 50 and $75 \%$ of the farmers experienced crop-raiding by macaques (Ramche: $55 \%$, Syafru: $70 \%$ and Timure: $65 \%)$. The IRs were highest for potato $(0.783, n=23$ farms), followed by maize $(0.697, \mathrm{n}=66$ farms $)$, buckwheat $(0.353, \mathrm{n}=17$ farms $)$ and millet $(0.357, \mathrm{n}=14$ farms). Pooling the cereals, the proportion of crops raided differed significantly among potato, maize and cereals $\left(\chi^{2}=7.12, \mathrm{df}=2, \mathrm{p}=0.028\right)$.

For all 3 crops, there was a negative correlation between the incidence of crop-raiding and distance to the forest (Fig. 1; Spearman rank correlation coefficient, all $\mathrm{n}=5: \rho=-0.975, \mathrm{p}=0.005$ for maize; $\rho=$ $-0.949, \mathrm{p}=0.014$ for potatoes; and $\rho=-0.949, \mathrm{p}=$ 0.014 cereal). For maize, the IR near the forest edge was $100 \%$ and remained high ( $80 \%)$ to $\sim 400 \mathrm{~m}$ from the forest; only at a distance greater than $400 \mathrm{~m}$ did the IR drop significantly to $<20 \%$. Similarly, for potato, IRs near the forest edge were between 80 and $100 \%$, but dropped to $50 \%$ at distances over $150 \mathrm{~m}$ from the forest. Finally, crop-raiding levels for cereal were $\sim 50 \%$ at distances $\leq 150 \mathrm{~m}$ from the forest and declined to $<20 \%$ at greater distances. 


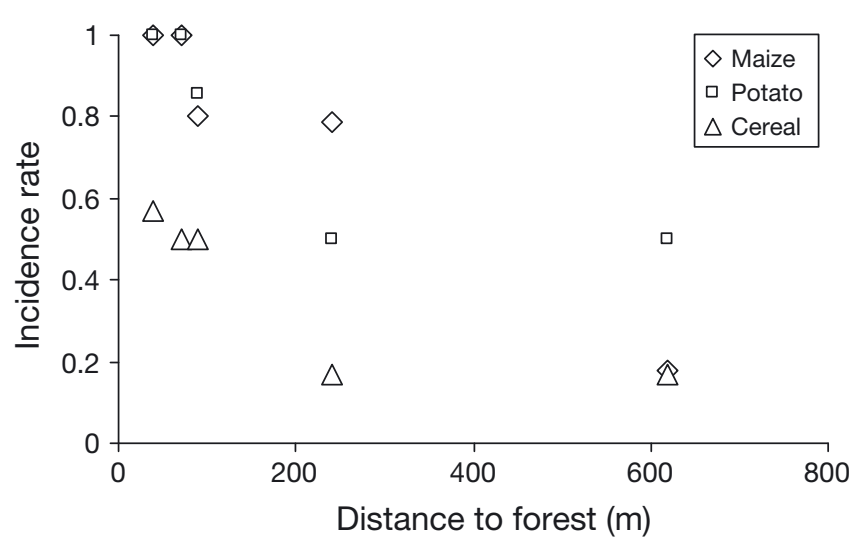

Fig. 1. Relationship between the incidence of crop-raiding of 3 types of crops by Assamese macaques and distance to the forest in Langtang National Park, Nepal

\section{Temporal variation in crop-raiding and mitigating damage caused}

Crop-raiding by Assamese macaques occurred throughout the day but mostly during the early morning hours (Fig. 2), with the animals retreating to the forests or rocky outcrops during the day. In the late afternoon, IRs of crop-raiding were very low. None of the farmers indicated that crop-raiding occurred during the night (if crop-raiding had occurred during the night, farmers would have noted this upon arrival on their fields in the early morning and noted it as such during the interviews). We found no significant temporal difference among the 3 crop types with respect to levels of crop-raiding $\left(\chi^{2}=6.90, \mathrm{df}=4, \mathrm{p}=0.15\right)$.

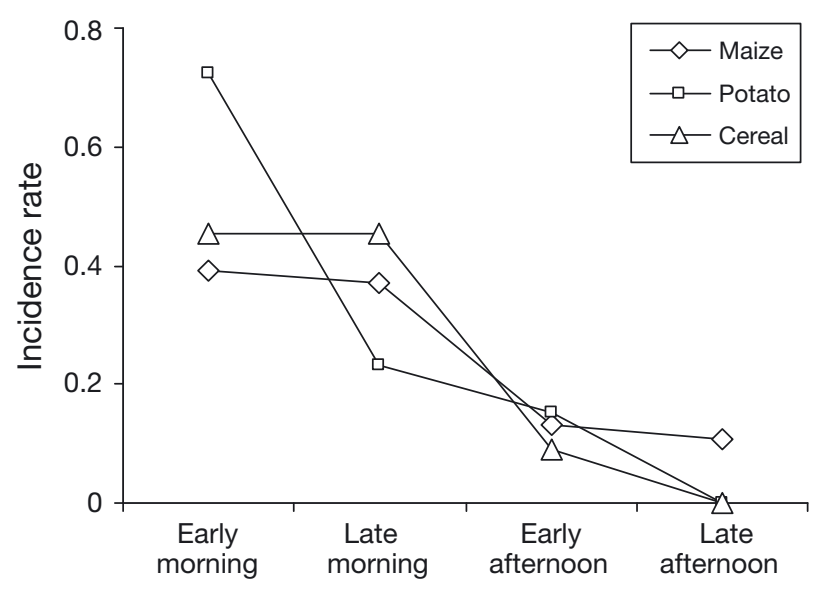

Fig. 2. Relationship between the incidence of crop-raiding of 3 types of crops by Assamese macaques and time of day in Langtang National Park, Nepal. In June, sunrise is at $\sim 05: 00 \mathrm{~h}$, and sunset is at 19:00 $\mathrm{h}$; early morning is ca. be-

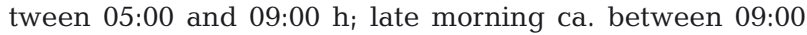
and 12:00 $\mathrm{h}$; early afternoon ca. between 12:00 and 15:00 $\mathrm{h}$; and late afternoon ca. between 15:00 and 19:00 h
We found that farmers did not distinguish among the different types of crops when it came to protecting them from crop-raiding by macaques (Fig. $3 ; \chi^{2}=$ 4.73, df $=4, p=0.35$ ). Most, if not all, farmers lined the outer periphery of their fields with thorny twigs and branches from trees and shrubs to deter the macaques from entering. The majority of farmers opted for active protection, including guarding, shouting (aided with slamming on tin boxes) or the use of a catapult. A smaller group preferred passive protection using scarecrows or dogs, which are mostly left on their own in the fields.

When queried about solutions to the problem of crop-raiding macaques both in Syafru (53\% of farmers) and Timure $(54 \%)$, the most commonly mentioned option was for the farmers to start growing crops that were less palatable to primates. In Ramche, however, $>40 \%$ of farmers were of the opinion that the best solution would be for the National Park to compensate them for the losses incurred. Overall, $<10 \%$ of farmers indicated that translocation of macaques (most likely to other parts of the park) would be the most desired solution.

\section{Intra-generic comparison of IRs in macaques}

Comparison with other studies on macaques that allowed us to calculate IRs (Table 1) shows that the pattern of crop-raiding in Assamese macaques is most similar to that described for booted macaques Macaca ochreata on Buton, Indonesia. At both sites, farmers experienced the highest levels of crop-raiding on maize and intermediate levels on (sweet) potatoes. Raids on fruit trees by long-tailed macaques M. fascicularis in Sumatra and toque macaques $M$. sinica in Sri Lanka, which raided cereals or tuber crops less extensively, resulted in fruit trees having the highest IRs

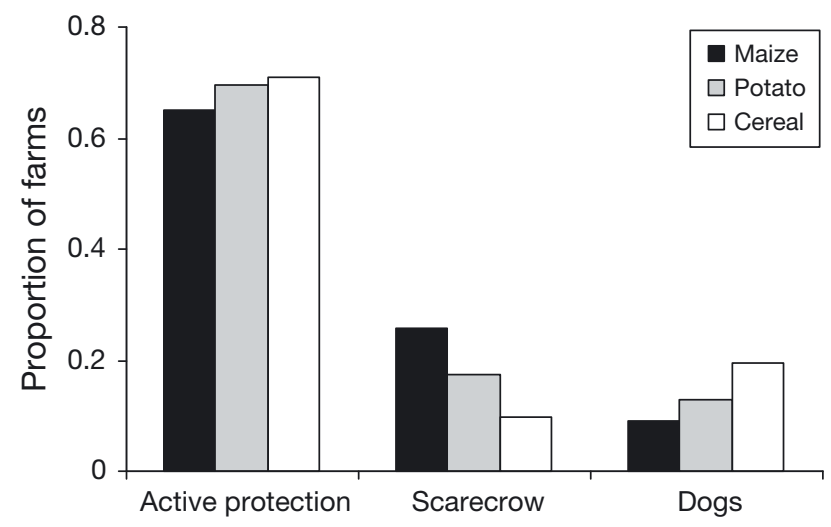

Fig. 3. Type of protection employed by farmers to reduce the level of crop-raiding in Langtang National Park, Nepal 


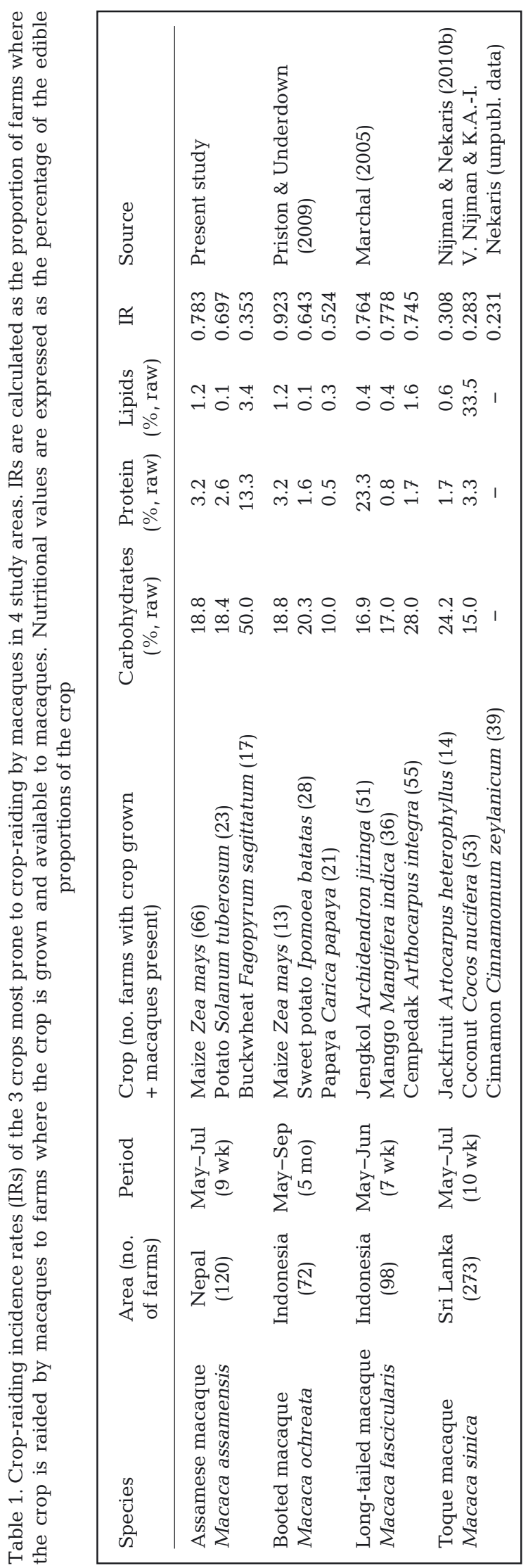

of all crops. Importantly, however, in Sumatra, IRs were generally high, but in Sri Lanka, they were considerably lower. In Nepal, a direct relationship exists between IR and the proportion of farms on which the crops are grown. In the other 3 studies presented in Table 1, different patterns emerge, and overall, no relation appears to exist between a crop's abundance (as measured by the number of farms on which it is grown) and likelihood of crop-raiding. Under the assumption that higher-quality crops are more susceptible to crop-raiding, we expect a positive relationship between IRs and caloric content or nutritional quality of the crops. However, data from Table 1 show that the relationship between amount of carbohydrates in these crops (grams per $100 \mathrm{~g}$ of raw food; data from www.nal.usda.gov/fnic/foodcomp/search) and IRs does not reach statistical significance (Spearman rank correlation coefficient, $\rho=-0.02, \mathrm{n}=11, \mathrm{p}=0.94$ ). Likewise, no statistically significant relationships occur between the amount of protein or the amount of lipids (fats) in crops and IRs ( $\rho=0.02, \mathrm{n}=11, \mathrm{p}=0.94$, and $\rho=-0.16, \mathrm{n}=11, \mathrm{p}=0.62$, respectively).

\section{DISCUSSION}

\section{General patterns of crop-raiding}

We report relatively high levels of crop-raiding as reported by farmers in 3 communities in Nepal. Cropraiding was highest for maize and potatoes, substantially less common for cereals and decreased with increasing distance between the farm and the nearest forest. In general, this pattern confirms previous studies conducted on crop-raiding by cercopithecids (Naughton-Treves 1998, Sillero-Zubiri \& Switzer 2001, Hill 2002, Gillingham \& Lee 2003, Marchal 2005, Priston 2005, Linkie et al. 2007, Nekaris et al. 2013). Factors other than the absolute distance from the forest may determine levels of crop-raiding. An important point to consider here is whether or not other farms are situated between the forest and the farm where the crop-raiding is measured; unfortunately, however, we were unable to analyse the relationship between crop-raiding and 'relative positions' of farms. Levels of tolerance toward the macaques were generally high, and the methods of protecting crops were largely benign to the macaques. This is in stark contrast to the findings in many other studies (reviewed by SilleroZubiri \& Switzer 2001, Hill 2002, Osborn \& Hill 2005). In general, in areas where people adhere to the tenets of religions tolerant to primates (such as Buddhism in Sri Lanka [Nijman \& Nekaris 2010a, Nekaris et al. 
2013] or Hinduism in Buton [Priston \& Underdown 2009, N. Priston pers. comm.]), crop-raiding by macaques seems to be endured to a large degree, and indeed, the farmers in Langtang National Park seem to be a case in point. As indicated in previous research on local attitudes toward primate crop-raiding in normally tolerant societies (Nijman \& Nekaris 2010a), there is a fine balance between acceptance and intolerance, with the frequency of contact between primates and humans being a crucial factor. Based on a smaller sample size of 79 farmers living in Langtang National Park, Chalise \& Johnson (2005) concluded that a positive attitude toward primate conservation was negatively correlated with the number of draft animals per household member. Hence, the more prosperous farmers become, the fewer positive primate-conservation sentiments they hold. Similarly, Riley (2010) reported on the changing attitudes of people towards primates in Indonesia, suggesting that while traditional knowledge and beliefs, such as social taboos, are important to conservation efforts, a reliance on culture for conservation is risky as traditional values may eventually be abandoned as socioecological and economic conditions change. Despite these relatively high levels of tolerance and benign methods of preventing crop-raiding, according to the farmers, crop-raiding by Assamese macaques occurred mainly in the early morning hours. Similar temporal patterns of crop-raiding have been employed by other primates. In Bwindi Impenetrable National Park, Uganda, the raiding of crops mostly in the early morning and the early evening by L'Hoest's monkeys Cercopithecus lhoesti was considered a strategy to minimise conflict with farmers (Ukizintambara 2008). Sumatran orang-utans Pongo abelii living in an agroforest likewise modified their foraging behaviour to living in a human-dominated landscape (CampbellSmith et al. 2011): crop raids occurred mostly in the late afternoon or evening when most farmers had returned to the village for the night. Hence, the strategies adopted by Assamese macaques in Langtang National Park may reflect a shift in foraging behaviour potentially to avoid conflict with farmers.

\section{IRs as a measure to predict crop-raiding}

We were able to compare our data from Langtang National Park with 3 previous studies on macaques that collected data in a similar way, allowing us to calculate IRs. We purposefully restricted our data collection in Nepal to a $9 \mathrm{wk}$ period at a time when crops were widely available to primates. Our crop-raiding
IRs are therefore only representative for this limited period and will differ during different parts of the year. For instance, in higher parts of Langtang National Park, it was reported that Nepalese grey langurs fed extensively on potatoes from November to December (resulting in high IRs) but almost completely ignored them at other times (hence very low IRs) (Sayers \& Norconk 2008). Likewise, Maganga \& Wright (1991), Naughton-Treves et al. (1998) and Linkie et al. (2007) demonstrated large temporal variations in crop-raiding primates in Tanzania, Uganda and Indonesia, respectively.

Comparison with other studies of macaques that allowed us to calculate IRs (Table 1) shows that the pattern of crop-raiding in Assamese macaques is most similar to that described for booted macaques in Sulawesi (Priston \& Underdown 2009). At both sites, farmers experienced the highest levels of crop-raiding on maize and intermediate levels on (sweet) potatoes. Marchal (2005) in Sumatra, Indonesia, and Nijman \& Nekaris (2010b) in Sri Lanka showed trees to have the highest IRs of all crops. Differences and similarities among these sites are due to a large number of factors, including but not restricted to the distance between fields and the forest, the type of crops grown, the amount and type of guarding by farmers, the number of macaques present in the study area, the length of the study period (with higher IRs for longer studies) and possibly biological differences among macaque species.

A potential caveat is that the study by Priston \& Underdown (2009) stands somewhat out from the other 3 studies (Marchal 2005, Nijman \& Nekaris $2010 \mathrm{~b}$, present study) in terms of sample size (smaller number of farms included in the study and smaller number of farms that grew specific crops) and study duration (with repeated visits to farms over the $5 \mathrm{mo}$ study period, covering a larger part of the growing season with changing crop phenologies).

A large number of farmers suggested that the most effective way to reduce crop-raiding is to grow crops that are less palatable to primates. Calculating IRs by pooling data from a large number of farms offers an empirical way of establishing what crops are most at risk rather than relying on the farmer's own experience or that of a small number of farmers. In Langtang National Park, we found some evidence of increased likelihood of crop-raiding for those crops that are grown in higher quantities (cf. Yihune et al. 2009 for geladas Theropithecus gelada in Ethiopia and Saj et al. 2001 for vervets in Uganda), but when the dataset was expanded to include other species of macaque, this relationship was no longer apparent. 


\section{Implications for crop-raiding mitigation policies}

Our study outlines a need for a better understanding of the context of crop-raiding as well as for practical tools to prevent or minimise the economic impact of crop-raiding events. As more and more detailed studies emerge on crop-raiding, including those that enabled verification and evaluation of the events, debates on the most effective means to mitigate crop-raiding are coloured by broadly contested debates on animal welfare, conservation and development. All agree that more effective management must draw on expertise and commitment from various levels of society, from the government down to communities, local smallholders and farmers. These parties, however, often disagree about the most effective division of responsibilities and about the fair share of total efforts that each should bear. Management of crop-raiding macaques ideally should take into account the behaviour and environment of humans and primates to alleviate and control the damage caused by the primates. We accept that the behaviour and perceptions of humans may unconsciously facilitate crop-raiding by macaques. This needs to be recognized by all parties involved if effective mitigation policies are to be identified. Mitigating crop-raiding should thus explicitly target local people and farmers, as well as the macaques and their habitat, and requires individual involvement of and positive actions by local people for crop management. Experience from Japan shows that a key factor in this approach is to reduce the food resources available to macaques, such as crops (by proper protection), unharvested fruit, garbage and disposed vegetables, in and around human settlements so as not to attract the macaques to the area (Nakagawa et al. 2010). In other areas, persuading primates to change their ranging patterns by offering artificial feeding stations away from human settlements has been demonstrated to be a cost-effective solution (Kaplan et al. 2011). When proper protection of crops or effectively culling crop-raiding animals is not an option, the best techniques for deterring crop-raiding are often centred around influencing the behaviour of the raiding animal. These techniques may occur at any stage of the crop-raiding cycle. To be effective, deterrents need to alter the cost-benefit ratio of the raiding event (Lee \& Priston 2005): if the real or perceived costs to the animal of obtaining crops outweigh its benefits, crop-raiding will eventually stop. These economic decisions are not fixed in time, and most crop-raiding animals and certainly primates do become habituated to deterrents, making adaptive and inexpensive deterrents the most effective. Simple and cheap deterrents, such as fences, guarding by people or dogs, throwing objects or making a loud noise, many of which are already employed in our study area, can be effective but probably only when used systematically. Crucially, as highlighted by Strum (2010), crop-raiding primates may have an energetic advantage over non-crop-raiding primates because of the high caloric content of cultivated crops. They can afford to sit and wait, needing only a short lapse in guarding to obtain the desired crops. Spurts of chasing primates are therefore ineffective. Deterrents work best when employed by the community as a whole, or at least concurrently by neighbouring farmers, on a continuous basis.

We furthermore accept that while the conflict starts with actual damage caused by macaques, human relationships within the management process may result in more severe social conflict (cf. Hill 2004). Thus, relationships among stakeholders with different concepts of value (e.g. farmers, non-farming villagers, national park management and tourists) may be a social factor making conflict more serious (Nakagawa et al. 2010). Even increased crop protection on one farm (e.g. better fencing, active protection or repellents) may inadvertently lead to social conflict among farmers as macaques may simply shift their raids to unprotected fields or adjacent farms. An integrative approach to reducing macaque-human conflicts is needed, an approach which not only adjusts interactions among macaques, habitat and humans but which also mitigates interactions among humans faced with the challenges of crop-raiding (cf. Riley 2007). The situation in Langtang National Park compares favourably with many other areas, but we anticipate that this may change over time. A shift in notions of responsibility in civil society as traditional societies disappear may lead to more and more people holding 'someone else', including government bodies such as the national park authorities, responsible for loss of their crops or other damage caused by wildlife (cf. Strum 2010). Our study suggests that mitigating crop-raiding by macaques in Langtang National Park would be best addressed by focussing on either the most frequently raided crops, i.e. those with highest IRs, or on the most valued cash crops and taking into account spatio-temporal patterns of crop-raiding as identified in the present study. More detailed nutritional analyses of wild and cultivated crops (especially during periods of crop-raiding) may reveal additional insight into the proximate mechanisms determining crop IRs. 
Acknowledgements. We thank the Department of National Parks and Wildlife Conservation of the Government of Nepal for granting permission to carry out the research, and are grateful to the farmers of Ramche, Syafru and Timure Village Development Committees for their participation. M. K. Chalise, J. R. Khatiwada, P. D. Ale and N. K. Upadhyay helped with the surveys. V. Marchal and N. Priston are thanked for their studies on crop-raiding macaques at their respective field sites in Sumatra and Buton. We are grateful to the Primate Society of Great Britain, People's Trust for Endangered Species and The Rufford Small Grants Foundation for financial support and to Idea Wild for providing field equipment. G.R.R. was supported by an Oxford Brookes Habitat Country Scholarship. We gratefully acknowledge the anonymous reviewers, whose comments helped improve the quality of this paper.

\section{LITERATURE CITED}

Agetsuma N (2007) Ecological function losses caused by monotonous land use induce crop raiding by wildlife on the island of Yakushima, southern Japan. Ecol Res 22:390-402

Bhuju UR, Shakya PR, Basnet TB, Shrestha S (2007) Nepal biodiversity resource book. Protected areas, Ramsar sites, and World Heritage sites. International Centre for Integrated Mountain Development, Ministry of Environment, Science and Technology and United Nations Environment Programme, Regional Office for Asia and the Pacific, Kathmandu

Butynski TM, Cortes J, Waters S, Fa J and others (2008) Macaca sylvanus. In: IUCN (2012) IUCN Red List of Threatened Species. www.iucnredlist.org (accessed 8 July 2012)

Campbell-Smith G, Campbell-Smith M, Singleton I, Linkie M (2011) Raiders of the lost bark: orangutan foraging strategies in a degraded landscape. PLoS ONE 6:e20962

Chalise MK (2010) A study of Assamese monkey in Sebrubeshi of Langtang National Park, Nepal. J Nat Hist Mus Tribhuvan Univ 25:1-7

Chalise MK, Johnson RL (2005) Farmer attitudes toward the conservation of 'pest' monkeys: the view from Nepal. In: Paterson JD, Wallis J (eds) Commensalism and conflict: the human-primate interface. American Society of Primatologists, Norman, OK, p 223-239

Deag JM (1977) The status of the Barbary macaque Macaca sylvanus in captivity and factors influencing its distribution in the wild. In: H. S. H. Prince of Monaco R, Bourne G (eds) Primate conservation. Academic Press, New York, NY, p 267-287

Gillingham S, Lee PC (2003) People and protected areas: a study of local perceptions of wildlife crop-damage conflict in an area bordering the Selous Game Reserve, Tanzania. Oryx 37:316-325

Gumert MD, Fuentes A, Jones-Engel L (2011) Monkeys on the edge. Ecology and management of long-tailed macaques and their interface with humans. Cambridge University Press, Cambridge

Hill CM (2002) Primate conservation and local communities. Ethical issues and debates. Am Anthropol 104: 1184-1194

Hill CM (2004) Farmers' perspectives of conflict at the wildlife-agriculture boundary: some lessons learned from African subsistence farmers. Hum Dimens Wildl 9: 279-286
Jackson R, Wangchuk R (2001) Linking snow leopard conservation and people-wildlife conflict resolution: grassroots measures to protect the endangered snow leopard from herder retribution. Endang Species Update 18: 138-141

Kaplan BS, O'Riain MJ, van Eeden R, King AJ (2011) A low-cost manipulation of food resources reduces spatial overlap between baboons (Papio ursinus) and humans in conflict. Int J Primatol 32:1397-1412

King FA, Lee PC (1987) A brief survey of human attitudes to a pest species of primate (Cercopithecus aethiops). Primate Conserv 8:82-84

Knight J (1999) Monkeys on the move: the natural symbolism of people-macaque conflict in Japan. J Asian Stud 58:622-647

Lammertink M, Nijman V, Setiorini U (2003) Population size, Red List status and conservation of the Natuna leaf monkey Presbytis natunae endemic to the island of Bunguran, Indonesia. Oryx 37:472-479

Lee PC, Priston NEC (2005) Human attitudes to primates: perceptions of pests, conflict and consequences for primate conservation. In: Paterson JD, Wallis J (eds) Commensalism and conflict: the human-primate interface. American Society of Primatologists, Norman, OK, p 1-23

> Linkie M, Dinata Y, Nofrianto A, Leader-Williams N (2007) Patterns and perceptions of wildlife crop raiding in and around Kerinci Seblat National Park, Sumatra. Anim Conserv 10:127-135

Maganga SLS, Wright RG (1991) Bark-stripping by blue monkeys in a Tanzanian forest plantation. Trop Pest Manag 37:169-174

Marchal V (2005) Primate crop-raiding: a study of local perceptions in four villages in North Sumatra, Indonesia. MSc dissertation, Oxford Brookes University, Oxford

Nakagawa N, Nakamichi M, Sigiuara H (2010) The Japanese macaques. Springer, Tokyo

> Naughton-Treves L (1998) Predicting patterns of crop damage by wildlife around Kibale National Park, Uganda. Conserv Biol 12:156-168

Naughton-Treves L, Treves A (2005) Socio-ecological factors shaping local support for wildlife: crop-raiding by elephants and other wildlife in Africa. In: Woodroffe R, Thirgood S, Rabinowitz A (eds) People and wildlife: conflict or coexistence? Cambridge University Press, Cambridge, p 252-277

Naughton-Treves L, Treves A, Chapman A, Chapman C, Wrangham R (1998) Temporal patterns of crop-raiding by primates: linking food availability in croplands and adjacent forest. J Appl Ecol 35:596-606

Nekaris KAI, Boulton A, Nijman V (2013) An ethnoprimatological approach to assessing levels of tolerance between human and commensal non-human primates in Sri Lanka. J Anthropol Sci 91 (in press)

Nijman V, Nekaris KAI (2010a) Changes in levels of tolerance towards commensal primates in relation to deforestation in Sri Lanka. Int J Pest Manag 56:153-158

Nijman V, Nekaris KAI (2010b) Testing a model for predicting primate crop-raiding using crop- and farm-specific risk values. Appl Anim Behav Sci 127:125-129

Nyhus PJ, Tilson R, Sumianto (2000) Crop-raiding elephants and conservation implications at Way Kambas National Park, Sumatra, Indonesia. Oryx 34:262-274

Nyhus PJ, Osofsky SA, Ferraro P, Madden F, Fisher H (2005) Bearing the cost of human-wildlife conflict: the challenge of compensation schemes. In: Woodroffe R, 
Thirgood S, Rabinowitz A (eds) People and wildlife: conflict or coexistence? Cambridge University Press, Cambridge, p 107-121

Osborn FV, Hill CM (2005) Techniques to reduce crop loss: human and technical dimensions in Africa. In: Woodroffe R, Thirgood S, Rabinowitz A (eds) People and wildlife: conflict or coexistence? Cambridge University Press, Cambridge, p 72-85

Pirta RS, Gadgil M, Kharshikar AV (1997) Management of the rhesus monkey Macaca mulatta and Hanuman langur Presbytis entellus in Himachal Pradesh, India. Biol Conserv 79:97-106

Priston NEC (2005) Crop-raiding by Macaca ochreata brunnescens in Sulawesi: reality, perceptions and outcomes for conservation. PhD thesis, University of Cambridge, Cambridge

Priston NEC, Underdown SJ (2009) A simple method for calculating the likelihood of crop damage by primates: an epidemiological approach. Int $\mathrm{J}$ Pest Manag 55: 51-56

Regmi GR, Kandel K (2008) Population status, threats and conservation measures of Assamese macaques Macaca assamensis in Langtang National Park, Nepal. Primate Eye 96:19-20

Riley EP (2007) The human-macaque interface: conservation implications of current and future overlap and conflict in Lore Lindu National Park, Sulawesi, Indonesia. Am Anthropol 109:473-484

Riley EP (2010) The importance of human-macaque folklore for conservation in Lore Lindu National Park, Sulawesi, Indonesia. Oryx 44:235-240

Saj TL, Sicotte P, Paterson JD (2001) The conflict between vervet monkeys and farmers at the forest edge in Entebbe, Uganda. Afr J Ecol 39:195-199

Sayers K, Norconk MA (2008) Himalayan Semnopithecus entellus at Langtang National Park, Nepal: diet, activity patterns, and resources. Int J Primatol 29:509-530

Schülke O, Pesek D, Whitman BJ, Ostner J (2011) Ecology of Assamese macaques (Macaca assamensis) at Phu Khieo Wildlife Sanctuary, Thailand. J Wildl Thailand 18:1-17

Sekhar NU (1998) Crop and livestock depredation caused by wild animals in protected areas: the case of Sariska

Editorial responsibility: Luigi Boitani,

Rome, Italy
Tiger Reserve, Rajasthan, India. Environ Conserv 25: 160-171

Siegel S (1956) Nonparametric statistics for the behavioural sciences. McGraw-Hill, New York, NY

Sillero-Zubiri C, Switzer D (2001) Crop raiding primates: searching for alternative, humane ways to resolve conflict with farmers in Africa. Wildlife Conservation Research Unit, Oxford University, Oxford

Sprague DS, Iwasak N (2006) Coexistence and exclusion between humans and monkeys in Japan: Is either really possible? Ecol Environ Anthropol 2:30-43

Srivastava A (1999) Primates of Northeast India. Megadiversity Press, Bikaner

Strum SC (1994) Prospects for management of primate pests. Rev Ecol Terre Vie 49:295-306

Strum SC (2010) Development of primate raiding: implications for conservation and management. Int J Primatol 31:133-156

Ukizintambara T (2008) Edge effects on ranging and foraging behaviour of L'hoest's monkey (Cercopithecus lhoesti) in Bwindi Impenetrable National Park, Uganda. Report to Rufford-Maurice Lang Foundation, London

Wallace GE (2010) Monkeys in maize: primate crop-raiding behaviour and developing on-farm techniques to mitigate human-wildlife conflict. PhD dissertation, Oxford Brookes University, Oxford

> Warren Y, Buba B, Ross C (2007) Patterns of crop-raiding by wild and domestic animals near Gashaka Gumti National Park, Nigeria. Int J Pest Manag 53:207-216

Yamada A, Muroyama Y (2010) Effects of vegetation type on habitat use by crop-raiding Japanese macaques during a food-scarce season. Primates 51:159-166

Yamagiwa J (2008) History and present scope of field studies on Macaca fuscata yakui at Yakushima Island, Japan. Int J Primatol 29:49-64

> Yihune M, Bekele A, Tefera Z (2009) Human-gelada baboon conflict in and around the Simien Mountains National Park, Ethiopia. Afr J Ecol 47:276-282

Zhou Q, Wei H, Huang Z, Huang C (2011) Diet of the Assamese macaque Macaca assamensis in lime-stone habitats of Nonggang, China. Curr Zool 57:18-25

Submitted: August 27, 2012; Accepted: February 4, 2013

Proofs received from author(s): May 18, 2013 